\title{
PHYSICS LEARNING DEVELOPMENT WITH APPLYING OUTDOOR INQUIRY APPROACH TO GROW STUDENT SCIENTIFIC WORK HABITS ON GRADE XI SENIOR HIGH SCHOOL
}

\author{
Riza Ayu Wardani ${ }^{* 1)}$, Zulhelmi $^{2)}$, M. Rahmad ${ }^{3)}$ \\ ${ }^{1,2,3)}$ Physics Education, Universits Riau \\ email: rizaayuwardani67@gmail.com \\ emi_zain@yahoo.co.id \\ m.rahmad@unri.ac.id
}

\begin{abstract}
The purpose of this research to produce learning devices by applying an outdoor-inquiry approach to fostering scientific work habits on the rotational dynamic material and the equilibrium of a valid rigid objects. The benefits of this research are the product can be used as teaching materials teacher guides, add science insight, guide students in self-development and foster the habits of student scientific work. Tthe method research was a Research and Development $(R \& D)$. Method steps include potentials and problems, literature studies and information gathering, product design, validation, and proven design. Data collection was done through learning device validation sheet by 5 validators, consisting of 3 physics education lecturers and 2 physics teachers. The instrument of learning device validity developed consisted of RPP validation instrument, LKPD and understanding items. Validation is done by two stages, that is validation phase I and validation phase II. The result of learning device validation phase I get the average value 2,78 with high category. The result of learning device validation phase II obtained the average value 3,15 with high category.
\end{abstract}

Keywords: outdoor-inquiry approach, rotational dynamics, scientific work.

\section{PENGEMBANGAN PERANGKAT PEMBELAJARAN FISIKA MENERAPKAN PENDEKATAN OUTDOOR-INQUIRY UNTUK MENUMBUHKAN KEBIASAAN BEKERJA ILMIAH SISWA KELAS XI SMA}

\author{
Riza Ayu Wardani ${ }^{* 1)}$, Zulhelmi $^{2)}$, M. Rahmad ${ }^{3)}$ \\ ${ }^{1,2,3)}$ Physics Education, Universits Riau
}

\begin{abstract}
Abstrak
Penelitian ini bertujuan untuk menghasilkan perangkat pembelajaran dengan menerapkan pendekatan outdoor-inquiry untuk menumbuhkan kebiasaan bekerja ilmiah pada materi dinamika rotasi dan keseimbangan benda tegar yang valid. Manfaat penelitian ini adalah produk dapat dijadikan sebagai bahan ajar panduan guru, menambah wawasan sains, menuntun siswa dalam pengembangan diri serta menumbuhkan kebiasaan bekerja ilmiah siswa. Metode penelitian yang digunakan adalah Research and Development (R\&D). Langkah-langkah metode meliputi potensi dan masalah, studi literatur dan pengumpulan informasi, desain produk, validasi, dan desain teruji. Pengumpulan data dilakukan melalui lembar penilaian validasi perangkat pembelajaran oleh 5 validator, terdiri dari 3 dosen pendidikan fisika dan 2 guru fisika. Instrumen validitas perangkat pembelajaran yang dikembangkan terdiri dari instrumen validasi


RPP, LKPD dan soal pemahaman. Validasi dilakukan dua tahap yaitu validasi tahap I dan validasi tahap II. Hasil validasi perangkat pembelajaran tahap I mendapatkan nilai rata-rata 2,78 dengan kategori tinggi. Hasil validasi perangkat pembelajaran tahap II diperoleh nilai rata-rata RPP 3,18 LKPD 3,30 dan Soal Pemahaman 2,98 dengan rata-rata seluruh perangkat 3,15 dengan kategoti tinggi.

Kata kunci: outdoor-inquiry, dinamika rotasi, bekerja ilmiah.

\section{Pendahuluan}

Hakikat pembelajaran fisika menuntut pemahaman konsep, prinsip maupun hukumhukum. Tujuan pembelajaran fisika disekolah menengah secara umum adalah memberikan bekal pengetahuan tentang fisika, kemampuan dalam keterampilan proses, serta meningkatkan kreativitas dan sikap ilmiah (Agung Setiawan, 2012). Pembelajaran fisika di SMA selama ini cenderung masih banyak yang didominasi oleh guru, siswa hanya menerima pengetahuan yang diberikan guru tanpa melalui pengolahan potensi yang ada. Sering kali guru lebih mendahulukan ketercapaian target kurikulum dan hasil akhir, akibatnya makna proses pembelajaran kurang dirasakan bagi bekal dalam memecahkan permasalahan kehidupan nya. Hal ini sesuai dengan apa yang dikatakan Tjia (2000), bahwa pengajaran fisika di sekolah lanjutan tingkat pertama (SLTP) maupun sekolah menengah atas (SMA) hanya menekankan satu proses pemahaman fenomena alam saja, yakni proses deduktif. Hal ini memang berhasil membuat anak menjadi kritis analitis, tetapi efek sampingnya membunuh kreativitas anak dalam menyisir fakta-fakta dari fenomena rumit untuk menghasilkan konsep hipotesis atau model teori yang sederhana.

Hasil penelitian Sopiah et al. (2009) menyatakan bahwa ketercapaian kebiasaan kerja ilmiah siswa masih tergolong rendah. Kebiasaan bekerja ilmiah belum tumbuh pada siswa dikarenakan keterbatasan waktu sehingga proses pembiasaan dan pemantauan yang dilakukan hanya dua kali. Tindak lanjut yang dapat dilakukan ialah pembelajaran kerja ilmiah terus dilaksanakan agar kebiasaan bekerja ilmiah dapat tumbuh pada siswa. Untuk lebih mendukung supaya membiasakan siswa bekerja ilmiah maka sebaiknya ditindak lanjuti pada mata pelajaran sains lainnya.

Keterbatasan sarana laboraturium dan peralatan praktikum menjadi permasalahan lain yang sering muncul terutama pada sekolah pinggiran. Hasil penelitian menunjuk kan bahwa secara umum potensi sarana laboratorium Fisika di SMA untuk mendukung pelaksanaan pembelajaran Fisika di SMA masih belum mencukupi (Indrawati, 2006). Hal ini meunjukkan bahwa kondisi laboratorium Fisika untuk memenuhi kebutuhan pelaksanaan pembelajaran Fisika di SMA masih kurang. Pemanfaatan laboraturium dalam mendukung pembelajaran juga masih sangat rendah, padahal dalam membahas Fisika tidak cukup hanya menekankan pada produk, tetapi yang lebih penting adalah proses untuk membuktikan atau mendapatkan suatu teori atau hukum. Oleh karena itu, alat peraga atau praktikum sebagai alat media pendidikan untuk menjelaskan IPA sangat diperlukan (Indrawati, 2006).

Dari pengamatan di lapangan, ternyata di sekolah-sekolah yang mempunyai laboratorium dengan peralatan eksperimen yang memadaipun, metode eksperimen jarang dilakukan (Zulirfan, et al., 2017). Berdasarkan hasil kajian Zulirfan, et al. (2013), alasan utama para guru terhadap persoalan ini adalah waktu yang tersedia dalam jam pelajaran sains di sekolah tidak mencukupi untuk menerapkan metode eksperimen, sedangkan konten atau pengetahuan sains yang harus diajarkan cukup padat.

Permasalahan tersebut perlu diatasi dengan mencari pendekatan pembelajaran sains yang mampu meningkatkan kemampuan memecahkan masalah (problem solving) serta dapat diterapkan dengan keterbatasan peralatan dan sarana laboraturium yang ada. Model pembelajaran sains dengan pendekatan inkuiri merupakan alternatif jawaban, karena pendekatan itu dapat memfasilitasi siswa untuk memecahkan masalah melalui penyelidikan ilmiah, sehingga siswa dapat menemukan sendiri jawabannya (McDemott et al. dalam Wiyanto, 2015). Hasil penelitian lain menunjukkan bahwa pembelajaran dengan 
kegiatan laboraturium berbasis inkuiri lebih baik dibandingkan dengan pembelajaran konvensional (Kaswan, 2005). Jaelani (2005) mengatakan bahwa pembelajaran berbasis inkuiri lebih meningkatkan penguasaan konsep siswa dibandingkan dengan pembelajaran biasa (ceramah dan mencatat) dan pembelajaran berbasis inkuiri dapat meningkat kan keterampilan proses sains siswa.

Untuk mengatasi permasalahan keterbatasan peralatan laboraturium dapat diguna kan pendekatan pembelajaran luar ruangan (outdoor), karena dengan model pembelajaran ini peralatan laboraturium yang dibutuhkan dapat diganti dengan benda-benda yang ada di sekitar kita. Hal ini sesuai dengan yang dikatakan oleh Popov (2006) bahwa objek dari pembelajaran fisika di luar ruangan (outdoor) adalah benda-benda yang ada di alam (buatan atau alami) yang dapat merefleksikan prinsip-prinsip, hukum dan teori fisika sehingga pengalaman berpikir, menggunakan peralatan fisika dan bendabenda lain, pandangan siswa tentang dunia ilmiah, kemampuan serta sikap siswa terhadap fisika dapat ditingkatkan.

Nation Science Teacher Asosiayion (NSTA) mendefinisikan dengan tegas bahwa inkuiri ilmiah merupakan cara yang paling baik untuk memahami materi IPA, karena siswa belajar bagaimana cara mengajukan pertanyaan dan menggunakan fakta-fakta untuk menjawab pertanyaan tersebut. Siswa juga belajar untuk merancang percobaan dan mengumpulkan bukti dari berbagai sumber, mengembangkan penjelasan dari data yang ada serta mengkomunikasikan dan mempertahankan kesimpulan mereka (NSTA dalam Wenning, 2007).

Pelajaran Fisika sering kali menjadi pelajaran yang tidak diminati karena banyak nya persamaan matematika, banyaknya konsep fisika yang harus dikuasai serta keterkaitan dengan kehidupan sehari-hari yang sangat sedikit (Popov, 2006). Salah satu cara mengatasi masalah ini adalah dengan memotivasi siswa dalam belajar fisika. Holubova (2005) mengatakan bahwa peningkatan motivasi siswa dapat dilakukan dengan membawa konsep fisika sedekat mungkin dengan kehidupan siswa untuk menyederhanakan dan memodivikasi praktikum serta menghubungkan berbagai disiplin ilmu. Pembelajaran di luar ruangan juga memberikan kesempatan yang cukup untuk mengembangkan konsep siswa sebab pembelajaran berada pada dunia nyata (Penwell, 2004).

Hal ini sesuai dengan penelitian tentang ingatan (memory) yang dilakukan Caine (dalam Knapp, 1992) yang menggambarkan dua jenis sistem memori yaitu "taxon" dan "lokale ". Taxon memory terlihat pada proses ingatan tentang pemberian informasi oleh orang lain. Disisi lain lokale memory secara otomatis membuat peta pikiran tentang lingkungan sekitar kita, peta ini yang membimbing pergerakan kita dan interaksi yang aman serta akurat. Pelajaran luar ruangan mampu memberikan memori locale yang membantu siswa mengkontruksi pengetahuan mereka dan pelajaran jadi penuh arti (meaningfull). Praktikum luar ruangan ini dapat dilakukan dengan membawa siswa melakukan observasi pada objek yang dipilih di lingkungan sekitar kita kemudian mencatat hasil pengamatan mereka dengan bahasa diskriptif, hasil pengukuran dan memberi label pada gambar dan foto. Popov (2006) mengatakan bahwa kegiatan outdoor dilakukan dengan mengguna kan peralatan yang cukup besar yang ada di sekitar kita.

Kebiasaan bekerja ilmiah diharapkan dapat menumbuhkan kebiasaan berpikir dan bertindak yang merefleksikan penguasaan pengetahuan, keterampilan, dan sikap ilmiah yang dimiliki siswa. Bila kebiasan (habit) tersebut sudah tumbuh pada siswa maka bekerja ilmiah dalam pembelajaran sains dapat dikatakan berhasil, yaitu siswa belajar menjadi seperti seorang ilmuwan (learning to be a scientist). Jadi hasil belajar yang dapat dikembangkan dalam pembelajaran sains dengan pendekatan inkuiri sesuai dengan kebiasaan bekerja ilmiah adalah kebiasaan berpikir dan bertindak yang merefleksikan penguasaan pengetahuan, keterampilan, dan sikap ilmiah yang dimiliki siswa (Lukman Hakim et al., 2017).

Tujuan penelitian ini adalah untuk mengembangkan perangkat pembelajaran fisika dengan pendekatan inkuiri melalui kegiatan di luar ruangan (outdoor). Tujuan khusus yang akan dicapai pada penelitian ini adalah untuk mengetahui validitas perangkat 
(RPP, LKPD, soal pemahaman) melalui outdoor-inquiry. Adapun manfaat penelitian ini adalah bagi guru dengan tersedianya perangkat pembelajaran diharapkan guru dapat mengembangkan perangkat pembelajaran, bagi siswa diharapkan penelitian ini dapat menumbuhkan kebiasaan bekerja ilmiah serta diharapkan dapat menyempurnakan pembelajaran Fisika dalam upaya meningkatkan kualitas pendidikan pada jenjang SMA.

\section{Bahan dan Metode}

Penelitian dilaksanakan di Laboratorium Pendidikan Fisika FKIP Universitas Riau. Pelaksanaan penelitian dimulai pada bulan Maret sampai bulan Mei tahun 2018. Adapun metode penelitian ini adalah metode penelitian dan pengembangan (Research and Development) yaitu metode penelitian yang menghasil kan produk tertentu dan menguji keefektifan produk tersebut. Secara garis besar ada tiga langkah penelitian dan pengembangan ini, yaitu 1) studi pendahuluan, 2) melakukan pengembangan produk, dan 3) menguji dan memvalidasi produk.

Rancangan penelitian dan pengembangan disingkat dengan 4D, yang merupakan perpepanjangan dari Define, Design, Development dan Dissemination. Hal ini dapat digambarkan seperti tertera pada Gambar 1.

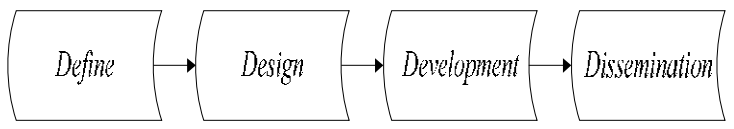

Gambar 1. Langkah-langkah penelitian dan pengembangan menurut Thiagaraja (Sugiyono, 2015).

Objek penelitian ini adalah perangkat pembelajaran berdasarkan pendekatan outdoor-inquiry berbasis kurikulum 2013 pada materi dinaamika rotasi daan kesetimbangaan benda tegar yang dikembangkan meliputi rencana pelaksanaan pembelajaran (RPP), lembar kerja peserta didik (LKPD), dan instrumen soal yang divalidasi oleh validator yang terdiri dari 3 orang dosen Program Studi Pendidikan Fisika FKIP Universitas Riau dan
2 orang guru SMA mata pelajaran fisika. Teknik analisis data yang digunakan dalam penelitian ini adalah analisis deskriptif, yakni dengan cara menghitung skor validitas dari setiap indikator validitas perangkat pembelajaran. Ditentukan oleh skor hasil validasi oleh dosen ahli dan guru. Menghitung validitas perangkat pembelajaran yang terdiri dari isi RPP, isi LKPD dan soal pemahaman dengan menggunakan skala Likert seperti pada Tabel 1.

Tabel 1. Skor penilaian angket

\begin{tabular}{lll}
\hline No & Kategori & Skor \\
\hline 1 & Sangat sesuai & 4 \\
2 & Sesuai & 3 \\
3 & Kurang sesuai & 2 \\
4 & Tidak sesuai & 1 \\
\hline
\end{tabular}

Sumber: Sugiyono, 2015.

\section{Hasil dan Pembahasan}

Data yang terkumpul pada penelitian ini adalah skor penilaian validasi RPP, LKPD, dan soal pemahaman yang diberikan oleh validator dengan menerapkan pendekatan outdoor-inquiry untuk menumbuhkan kebiassaan bekerja ilmiah siswa kelas XI SMA materi dinamika rotasi dan keseimbangan benda tegar. Hasil penilaian perangkat pembelajaran fisika menerapkan pendekatan outdoor-inquiry untuk menumnuhkan kebiasaan bekerja ilmiah dapat dilihat pada Tabel 2.

Berdasarkan Tabel 2 perangkat pembelajaran pendekatan outdoor-inquiry untuk menumbuhkan kebiasaan bekerja ilmiah belum valid karena masih ada indikator penilaian yang rendah. Maka dilakukan validasi kedua, dengan hasil sebagai sebagaimana pada Tabel 3.

Berdasarkan Tabel 3 perangkat pembelajaran yang terdiri dari RPP, LKPD dan soal pemahaman dinyatakan valid dengan kategori rata-rata tinggi dan dinyatakan layak digunakan sebagi perangkat pembelajaran disekolah. 
Tabel 2. Hasil penilaian perangkat pembelajaran fisika menerapkan pendekatan outdoor-inquiry untuk menumbuhkan kebiasaan bekerja ilmiah tahap pertama

\begin{tabular}{cccc}
\hline No & Indikator Penilaian & $\begin{array}{c}\text { Rata-rata } \\
\text { Penilaian }\end{array}$ & Kategori \\
\hline 1 & RPP 1 & 3,07 & $\mathrm{~T}$ \\
2 & RPP 2 & 2,60 & $\mathrm{~T}$ \\
3 & LKPD 1 & 3,20 & $\mathrm{~T}$ \\
4 & LKPD 2 & 3,00 & $\mathrm{~T}$ \\
5 & Soal Pemahaman 1 & 2,40 & $\mathrm{R}$ \\
6 & Soal Pemahaman 2 & 2,40 & $\mathrm{R}$ \\
\hline
\end{tabular}

Tabel 3. Hasil penilaian perangkat pembelajaran fisika menerapkan pendekatan outdoor-inquiry untuk menumbuhkan kebiasaan bekerja ilmiah tahap kedua

\begin{tabular}{cccc}
\hline No & Indikator Penilaian & $\begin{array}{c}\text { Rata-rata } \\
\text { Penilaian }\end{array}$ & Kategori \\
\hline 1 & RPP 1 & 3,36 & $\mathrm{ST}$ \\
2 & RPP 2 & 3,00 & $\mathrm{~T}$ \\
3 & LKPD 1 & 3,30 & $\mathrm{~T}$ \\
4 & LKPD 2 & 3,31 & $\mathrm{ST}$ \\
5 & Soal Pemahaman 1 & 2,97 & $\mathrm{ST}$ \\
6 & Soal Pemahaman 2 & 3,00 & $\mathrm{~T}$ \\
\hline \multicolumn{2}{l}{ Rata-rata } & 3,15 & $\mathrm{~T}$ \\
\hline
\end{tabular}

Berdasarkan data hasil validasi perangkat pembelajaran yang telah diuraikan diatas diperoleh hasil akhir bahwa seluruh komponen perangkat pembelajaran yang telah penulis kembangkan pada materi pokok dinamika rotasi dan kesetimbangan benda tegar dengan menerapkan outdoor-inquiry untuk menumbuhkan kebiasaan bekerja ilmiah model mempunyai indeks validitas tinggi atau sangat tinggi dengan nilai rata-rata 3.15. Ini berarti perangkat pembelajaran tersebut dinyatakan valid. Validitas perangkat tersebut pada umumnya berkategori tinggi dan sangat tinggi. Dengan demikian perangkat pembelajaran fisika layak untuk digunakan. Kajian tersebut sejalan dengan hasil penelitian yang mendapatkan perangkat pembelajaran yang valid dan praktis sebagai indikator kelayakan perangkat pembelajaran (M. Rahmad \& Nordin, 2017). Perangkat pembelajaran yang valid dapat memenuhi tujuan penelitian ini yaitu menumbuhkan kebiasaan bekerja ilmiah. Hal ini sesuai dengan penelitian yang dilakukan Damayanti (2005) yang mengatakan bahwa perangkat pembelajaran inkuiri dapat mengembangkan sikap ilmiah siswa.

\section{Kesimpulan dan Saran}

Perangkat pembelajaran yang peneliti kembangkan pada penelitian ini berupa RPP, LKPD dan tes soal pemahaman. Berdasarkan data dan analisis data sebelumnya, maka diperoleh perangkat pembelajaran yang valid dengan validitas kategori tinggi. Perangkat pembelajaran yang valid dan praktis sebagai indikator kelayakan perangkat pembelajaran, dengan demikian perangkat pembelajaran fisika layak untuk digunakan.

Terkait penelitian ini, pengkaji menggunakan pendekatan $\mathrm{R} \& \mathrm{D}$ yang terdiri 
dari 4 tahap yaitu define, design, development, and dissemination. Namun pada pelaksanaan nya, peneliti hanya sampai pada tahap development sehingga teruji secara internal. Maka dari itu penulis merekomendasikan agar penelitian ini dilanjutkan ke tahap dissemination yaitu melakukan uji coba berupa penerapan ke sekolah dan menyebarluaskan produk yang telah teruji untuk dimanfaatkan orang lain. Penulis juga merekomendasikan untuk dapat mengatur alokasi waktu dengan baik dan menyamakan tingkat kesulitan soal agar siswa dapat menguasai konsep.

\section{Daftar Pustaka}

Agung Setiawan, 2012. Metode Praktikum dalam Pembelajaran Pengantar Fisika SMA: Studi pada Konsep Besaran dan Satuan Tahun Ajaran 2012-2013. Jurnal Pembelajaran Fisika, 1(3), Diakses 20 Januari 2018.

Holubova, R., 2005. Environmental Physics: Motivation in Physics Teaching and Learning. Journal Physics Teacher. Education Online, 3(1), 17-20.

Indrawati, 2006. Potensi Laboraturium Fisika di SMA dalam Mendukung Pelaksanaan Pendidikan. Depdiknas, Jakarta.

Jaelani, 2005. Pembelajaran Suhu dan Kalor Berbasis Inkuiri untuk Meningkatkan Penguasaan Konsep dan Keterampilan Proses Sains Siswa MTs. Tesis. PPs UPI, Bandung.

http://sps.upi.edu/v3/?page=abstrak\&opt ion $=$ tesis\&action $=$ view\&id $=039332$.

Kaswan, 2005. Peningkatan Pemahaman Konsep dan Kemampuan Berpikir Kritis Siswa melalui Kegiatan Laboraturium Berbasis Inkuiri pada Pokok Bahasan Rangkaian Listrik Arus Searah. Tesis. PPs UPI. Bandung.

http://sps.upi.edu/v3/?page=abstrak\&opt ion $=$ tesis\&action $=$ view\&id $=039333$

Knapp, C., 1992. Thinking in Outdoor Inquiry. http://www.ed.gov/ERIC_Digests/ed348 198.html. Diakses Tanggal 18 Januari 2018.

Lukman Hakim, Suparmi, \& Muhammad Masyuri. 2017. Pengembangan Model Pembelajaran Fisika Melalui OutdoorInquiry untuk Menumbuhkan Kebiasaan Bekerja Ilmiah pada Materi Momen
Gaya, Fluida, dan Keseimbangan Statis di IKIP PGRI Pontianak. Jurnal Inkuiri, 6(3), 153-162.

M. Rahmad \& Norazah Mohd Nordin, 2017. Pengembangan perangkat pembelajaran elektronika dasar berbasis web dengan penerapan PBL. Jurnal Geliga Sains, $5(1), 47-53$.

Penwell, R., 2004. Advance Placement Environmental Science: Implication of Gender and Ethnicity. Electronic Journal of Science, 8(3).

Popov, O., 2006. Developing Outdoor Activities and a Website as resources to Stimulate Learning Physics in Teacher Education. Journal Physics Teacher. Education Online, 3(3), 18-23.

Sugiyono, 2015. Metode Penelitian dan Pengembangan Research \& Development. Alfabeta, Bandung.

Tjia May On, 2000. Pengajaran Fisika Membunuh Kreativitas. Artikel Konferensi Guru Fisika Indonesia. Kompas, edisi Senin Mei 2000.

Wenning, C.J., 2007. Assesing Inquiry Skill as Component of Scientific Literacy. Journal Physics Teacher. Education Online, 4(2), 21-24.

Wiyanto, 2015. Menyiapkan Guru Sains Mengembangkan Kompetensi Laboratorium. Universitas Negeri Semarang Press. Semarang. http://www.depdiknas.go.id/jurnal/64/j6 4_06.pdf.

Zulirfan, Subahan Mohd Meerah, \& Zanaton Hj. Ikhsan, 2013. Early study in developing take-home physics experiment: an alternative strategy to improve science process skills and scientific attitudes. Prosiding Seminar Serantau UKM-Unri.

Zulirfan, Zanaton Hj. Ikhsan, \& Subahan Mohd Meerah, 2017. Pengembangan kit take-home experiment cahaya dan Optik sebagai media pembelajaran sains siswa SLTP. Jurnal Geliga Sains, 5(1), 1-7. 